\title{
Social Deprivation of Newborn Rats Modifies Exploratory and Defensive Behavior at Mature Age
}

\author{
Anna Yu. Shishelova, Kirill S. Smirnov, Vladimir V. Raevskiy \\ Institute of Higher Nervous Activity and Neurophysiology of RAS Moscow, Moscow, Russia \\ Email: ihna_ann@mail.ru, smirnov.kirill.sc@gmail.com,vraevsky@mail.ru
}

How to cite this paper: Shishelova, A.Yu., Smirnov, K.S. and Raevskiy, V.V. (2019) Social Deprivation of Newborn Rats Modifies Exploratory and Defensive Behavior at Mature Age. Journal of Behavioral and Brain Science, 9, 375-384.

https://doi.org/10.4236/jbbs.2019.910028

Received: September 1, 2019

Accepted: October 19, 2019

Published: October 22, 2019

Copyright $\odot 2019$ by author(s) and Scientific Research Publishing Inc. This work is licensed under the Creative Commons Attribution International License (CC BY 4.0).

http://creativecommons.org/licenses/by/4.0/

\begin{abstract}
The effect of complete social deprivation in early postnatal ontogenesis on adult behavior in $\mathrm{Wag} / \mathrm{Rij}$ rats with a genetic predisposition to the development of absence epilepsy was studied. From the $2^{\text {nd }}$ to the $8^{\text {th }}$ day of life, a 3-hour daily isolation of the pups from the mother and siblings was performed, the control animals were handled. In adulthood, offspring behavior was tested in an elevated plus-maze, an open field, and for an ability to learn the conditioned reflex of active avoidance. In isolated earlier rats, an increase in emotional reactivity, exploratory behavior in a potentially dangerous space, the speed of learning a conditioned reflex with negative painful reinforcement, and a disturbance of the formation of a defensive reaction were revealed. It is assumed that high emotional reactivity creates the prerequisites for the development of absence epilepsy.
\end{abstract}

\section{Keywords}

Ontogenesis, Absence Epilepsy, Behavior, Wag/Rij Rats

\section{Introduction}

An important factor in early ontogenesis, which affects the morphological and functional development and manifestation of adaptive behavior in adulthood, is species-specific information. The deprivation of sensory input in the first 3 weeks of life due to clipping of vibrissae causes a change in the formation of early behavioral reactions [1], and vibrissectomy from the $9^{\text {th }}$ to the $20^{\text {th }}$ day of postnatal ontogenesis determines a more stereotyped behavior of adult animals in the new environment [2]. Largely the quality of maternal care has an effect on the development of the functions of the newborn [3] [4] [5] [6] [7]. We have 
shown that the dynamics of the formation of exploratory behavior in Wistar rats depends on the experience of motherhood in lactating female [3].

From the first day of life, sensory influx is especially important for individuals with congenital pathology. Thus, in WAG/Rij rats genetically predisposed to absence epilepsy, sensory deprivation in the first 3 weeks of life leads to an earlier manifestation of the pathology [8]. At the same time, environmental modification by nursing WAG/Rij rat pups with healthy lactating Wistar females decelerates the onset of epilepsy attacks [9] [10]. Together, the results of previous studies suggest that the restriction of maternal care can change the dynamics of the formation of early behavior reactions, emotional status and adaptive behavior in adulthood, which may aggravate the development of a genetically predetermined pathology. Thus, daily separation of pups from their mothers for 3 - 4 hours induces a change in early defensive behavior [11], reactivity of the hypothalamic-pituitary-corticoid system, and behavior in adult animals [11] [12]. Due to the fact that the mother must leave the nest from time to time in natural habitat of rats, experiments with the removal of the female from rat pups for a period of 3 hours should not be considered as significant deprivation. We assume that for an estimation of the significance of species-specific information of early ontogenesis, it should be considered a complex of factors. It is not only maternal care, but also by interaction with siblings and a comfortable state in nest habitat. A disturbance of the development of intact rat pups nursed together with vibrissectomized siblings testifies to this [1]. In this connection, in order to identify the significance of social factors of early ontogenesis in the development WAG/Rij rats, individual isolation of pups from the nest was performed, which deprives pup from the entire complex of species-specific sensory signals.

\section{Material and Methods}

The work was performed on laboratory-bred WAG/Rij rats which born by 7 nulliparous females. All experiments were performed in accordance with the requirements of the Council of the European Union Directive (86/609/EEC) on the use of animals for experimental research. Throughout the study, animal care comprised a reversed 12-hr light-dark cycle with a $20.00-8.00$ dark phase, temperature at $21^{\circ} \mathrm{C} \pm 1{ }^{\circ} \mathrm{C}$. Pregnant dams were caged individually before delivery. Pups day of birth was designated as PND (postnatal day) 1. Litters were inspected at PND 2. Eight rat pups were left in each litter (usually 4 males and 4 females, in one litter there were 6 males and 2 females). In two litters, by the second day of life, there were 4 rat pups (two males and two females). Social isolation was performed daily from PND 2 to 8 in five litters. Isolation comprised temporary removal of the dam from the home cage; removal of the pups from the home cage; and placement of the pups on sawdust in round plastic containers (diameter of $9.8 \mathrm{~cm}$ and a height of $4.3 \mathrm{~cm}$ ) in the home vivarium, individually, for 3 hours in the afternoon (experimental group, by the $8^{\text {th }}$ day of life 18 males, 13 females). In two litters, only an inspection of pups at PND 2 and PND 
8 was performed (control group, by the $8^{\text {th }}$ day of life, 8 males, 8 females). All pups were weighed at the age of 2, 8, 20 days and in adulthood (60 days).

At PND 27, subjects were sexed, weaned from the dam and caged in same-sex groups of 3 - 4. In adulthood, the behavior of males was tested in the elevated plus-maze (EPM) for $5 \mathrm{~min}$ [13] at the age of 2 months and through two weeks in the "open field" [14] [15] for $10 \mathrm{~min}$. The EPM consisted of 4 arms constructed of black opaque plastic: two open and two enclosed by walls, each $45 \mathrm{~cm}$ long, with the like arms situated opposite each other, in the shape of a plus, with a central open area measuring $10 \times 10 \mathrm{~cm}$. The maze was elevated above the floor to a height of $80 \mathrm{~cm}$. The rats were placed in the center of the maze and then allowed to run either into the open or closed arms of the maze. In the EPM paradigm, closed arms are a comfortable area for rats, open corridors cause fear and anxiety, prompting them to be avoided, and at the same time prompting them to explore a new space [13]. The "open field" was a square, black arena $(108 \times 108 \mathrm{~cm})$ and with $40 \mathrm{~cm}$ high walls. The test began by placed rats in the center of the "open field".

Locomotor and exploratory activity was estimated using automated video tracking software. The behavior of the animal was recorded with a video camera which is positioned above the center of the test apparatus. The recording computer was located in the next room. Image control, recording, and analysis were performed using the Easy Track software, which determined the $x-y$ coordinates of rat position (central point of the rat's image) every $40 \mathrm{~ms}$. The coordinates were used to create the path of locomotion (track) and to calculate the kinematic characteristics of the locomotion. The locomotor activity common for the entire test space and for individual zones were evaluated: in the open field-in the central zone (square in the center of the field), in the EPM-in closed arms, in open arms and on the central platform. By visual observation, the quantity of rearing and climbing, grooming, defecations in both tests, hanging from the central platform and open arms in the EPM was recorded. The length of track, the mean speed of locomotion $\left(\mathrm{V}_{\mathrm{m}}\right)$, the maximum speed of locomotion for the test period $\left(\mathrm{V}_{\max }\right)$, the time spent without visible locomotion (duration of "sitting") were analyzed.

At the age of 6 - 6.5 months animals were exposed aversively motivated learning of two-way active avoidance in "shuttle box" [16]. The test apparatus was a plexiglas chamber $(26 \times 61 \mathrm{~cm}$ wide $\times 29 \mathrm{~cm}$ high $)$ with floor made of parallel stainless-steel bars $6 \mathrm{~mm}$ diameter stainless steel rods spaced $6 \mathrm{~cm}$ apart. The box was divided into two equal-sized compartments by a wall with an opened hole for rat transition between compartments. The chamber floor was connected to an ESL-2 electric stimulator using a current stabilizer (Linear Isolator DL360). A sound signal ( $80 \mathrm{~dB})$ supplied through a speaker mounted in the chamber wall was used as a conditioned stimulus. As an unconditional stimulus, electrodermal stimulation of the limbs of the animal (footshock) was used. The intensity of footshock ( $\mathrm{mA}$ ) corresponded to the threshold for the reaction of 
withdrawal of the limbs from the floor.

Initially, rats were placed in the shuttle box and allowed to freely explore the apparatus for $15 \mathrm{~min}$. Then, they received 50 shuttle training trials. Each trial consists of conditioned stimuli paired with subsequent unconditioned stimuli. The duration of the conditioned stimulus was 5 seconds. An unconditional stimulus was presented 4.5 seconds after the conditional stimulus was started and continued until the animal crossed to the other compartment (maximum duration of $40 \mathrm{~s}$ ). The interval between trials was 20 - 40 seconds. If the rat showed a passive reaction in 10 trials (freezing and lack of movement during the presentation of a footshock), its training was stopped (there were 3 such animals in the control group and 2 in the experimental group).

The shuttle-box was connected to a computer for control of the training procedure. The rat responses were observed by using of video camera mounted above the apparatus. The latencies of avoidance and escape responses were recorded by pressing a key on the keyboard.

The following learning indicators were analyzed: 1) the total number of avoidance responses (as a percentage of 50 trials); 2) the serial number of the trial in which the animal exhibited the first avoidance response; 3 ) the maximum number of avoidance responses that occur in sequential trials; 4) the serial number of the trial, starting from which the conditioned avoidance reflex was stable (the criterion for learning was taken to be the presence of 9 avoidance responses in 10 consecutive trials).

\section{Statistical analysis}

Data were analyzed by Shapiro-Wilk test to estimate the distributions normality, nonparametric Mann-Whitney $\mathrm{U}$ test, Median test (in the text is designated as $\mathrm{M}$ ), Wilcoxon matched pair test (in in the text this test is designated as $\mathrm{T}$ ) and Kruskall-Wallis test, test for difference between two proportions (Z-test) (STATISTICA software, Ver. 10.0).

\section{Results}

\section{The effect of isolation on the weight of rat pups}

There were no significant differences in the weight at PND 2 (before the isolation procedure from the mother and siblings) between the control and experimental groups (Table 1). At PND 8 (immediately after the isolation procedure),

Table 1. Body weight (g, mean \pm S.D.) of rat pups housed under different conditions.

\begin{tabular}{ccc}
\hline Postnatal day & Control group $(\mathrm{n}=16)$ & Experimental group $(\mathrm{n}=23)$ \\
\hline 2 & $6.56 \pm 0.81$ & $6.48 \pm 0.67$ \\
8 & $17.25 \pm 1.73$ & $14.0 \pm 1.94^{\star}$ \\
20 & $36.5 \pm 1.83$ & $\mathrm{p}=0.000019$ \\
& & $33.17 \pm 3.21^{\star}$ \\
\end{tabular}

${ }^{*} \mathrm{p}<0.001$ for control versus experimental groups ( $U$ test). 
statistically significantly lower weight was observed in experimental rats. These differences persisted until PND 20 (period of milk nursing finishing). In adulthood, the weight of the males of the experimental and control groups did not differ and amounted to $199.47 \pm 23.05 \mathrm{~g}$ (mean \pm S.D.) and $203.75 \pm 19.65 \mathrm{~g}$, respectively.

\section{The effect of isolation on behavior in an elevated plus-maze}

Isolation in early ontogenesis influenced on the behavior of rats in an elevated plus-maze. Experimental animals had defecations (acts of defecation occurred in $47 \%$ of rats of this group), while in control rats there were none (differences are statistically significant, two-sided Z-test, $\mathrm{p}=0.0187$ ). The common length of track (mean \pm S.D. $=1277.24 \pm 149.19 \mathrm{~cm}, \mathrm{n}=8), \mathrm{V}_{\max }(40.84 \pm 9.09 \mathrm{~cm} / \mathrm{s})$ in the EPM as well as $\mathrm{V}_{\max }$ in the central platform $(25.15 \pm 4.05 \mathrm{~cm} / \mathrm{s})$ in experimental animals were higher compared to the control ones $(1125.70 \pm 194.20 \mathrm{~cm}, 32.83 \pm$ 6.79 and $21.69 \pm 2.43 \mathrm{~cm} / \mathrm{s}, \mathrm{n}=17$, respectively). The differences are statistically significant $(\mathrm{p}=0.021, \mathrm{p}=0.039, \mathrm{p}=0.0156$ respectively, $\mathrm{U}$ test). A comparative analysis of the behavior in the closed arms did not reveal differences between the control and experimental groups. Most animals of both groups came into open arms (88\% in each group). No differences between control and experimental groups were found in the amount of time spent in open and closed arms. At the same time, significant differences in the behavior of open arms were observed ( $M$ test, $\mathrm{p}<0.05$, Table 2). The length of track and the speed of locomotion in the open arms in the experimental animals were greater in comparison with control rats (Table 2).

\section{The effect of isolation on open field behavior}

The behavior of the animals was tested separately during the first $\left(t_{1}\right)$ and subsequent $\left(t_{2}\right)$ five minutes of being in the open field (Table 3 ). The behavior of rats during the first five minutes in the open field is equally determined by anxiety in an unfamiliar environment, and exploratory activity. The data of the subsequent 5 -minute testing more specifically reflect exploratory behavior [15].

The results obtained indicate the presence of at least two fundamental differences in the behavior of isolated in early ontogenesis and control rats. In control animals, no changes in the locomotor activity were observed in the periods $t_{1}$

Table 2. Behavior of control and experimental rats noted in the open arms of the Elevated Plus-Maze (mean \pm S.D.).

\begin{tabular}{|c|c|c|c|}
\hline The behavior variables in open arms & $\begin{array}{l}\text { Control group } \\
\qquad(\mathrm{n}=7)\end{array}$ & $\begin{array}{l}\text { Experimental group } \\
\qquad(\mathrm{n}=15)\end{array}$ & $\mathrm{p}$ ( $M$ test $)$ \\
\hline Time spent, s & $17.32 \pm 19.51$ & $40.68 \pm 31.23$ & $\mathrm{p}=0.1697$ \\
\hline Track length, $\mathrm{cm}$ & $48.39 \pm 70.22$ & $149.71 \pm 139.04$ & $\mathrm{p}=0.0221^{\star}$ \\
\hline $\mathrm{V}_{\mathrm{m}}, \mathrm{cm} / \mathrm{s}$ & $2.42 \pm 0.68$ & $3.34 \pm 1.11$ & $\mathrm{p}=0.1697$ \\
\hline $\mathrm{V}_{\max }, \mathrm{cm} / \mathrm{s}$ & $9.58 \pm 4.69$ & $18.55 \pm 10.61$ & $\mathrm{p}=0.021^{\star}$ \\
\hline duration of "sitting" (\% relative to time spent) & $42.84 \pm 17.97$ & $45.39 \pm 12.13$ & $\mathrm{p}=0.6471$ \\
\hline
\end{tabular}

${ }^{*} \mathrm{p}<0.05$ for control versus experimental groups ( $M$ test). 
Table 3. Behavior variables that was different in control and experimental rats noted in the open field during $t_{1}$ and $t_{2}$ periods (mean \pm S.D.).

\begin{tabular}{|c|c|c|c|c|}
\hline \multirow{2}{*}{ Behavior variables } & \multicolumn{2}{|c|}{ Control group $(n=8)$} & \multicolumn{2}{|c|}{ Experimental group $(\mathrm{n}=17)$} \\
\hline & $t_{1}$ & $t_{2}$ & $t_{1}$ & $t_{2}$ \\
\hline Track length, $\mathrm{cm}$ & $1565.44 \pm 562.57$ & $1448.39 \pm 595.81$ & $\begin{array}{c}2114.91 \pm 669.09^{*} \\
p=0.044\end{array}$ & $\begin{array}{c}1414.15 \pm 598.47 @ \\
p=0.000293\end{array}$ \\
\hline $\begin{array}{c}\text { Total time spent running } \\
\text { (locomotion with speed } \\
\text { more } 30 \mathrm{~cm} / \mathrm{s} \text { ), s }\end{array}$ & $16.92 \pm 13.41$ & $16.16 \pm 7.79$ & $\begin{array}{c}29.15 \pm 16.06^{*} \\
p=0.041\end{array}$ & $\begin{array}{c}15.58 \pm 11.60 @ \\
\mathrm{p}=0.001184\end{array}$ \\
\hline duration of "sitting", $s$ & $146.81 \pm 31.61$ & $154.03 \pm 61.01$ & $118.65 \pm 37.37$ & $\begin{array}{c}164.84 \pm 43.88 @ \\
p=0.000293\end{array}$ \\
\hline $\mathrm{V}_{\mathrm{m}}, \mathrm{cm} / \mathrm{s}$ & $5.22 \pm 1.88^{\star}$ & $4.83 \pm 1.99^{*}$ & $\begin{array}{c}7.05 \pm 2.23 * \\
p=0.021\end{array}$ & $\begin{array}{l}4.71 \pm 1.99 @ \\
p=0.000293\end{array}$ \\
\hline $\begin{array}{l}\text { Number of grooming } \\
\text { acts }\end{array}$ & $0.75 \pm 0.46$ & $1.0 \pm 1.07$ & $2.35 \pm 2.32$ & $\begin{array}{c}2.77 \pm 2.33^{*} \\
p=0.038\end{array}$ \\
\hline
\end{tabular}

* $-\mathrm{p}<0.05$ for control versus experimental groups ( $U$ test); @- $\mathrm{p}<0.01$ for period $t_{1}$ versus $t_{2}(T$ test).

and $t_{2}$, while in experimental rats the length of track and $\mathrm{V}_{\mathrm{m}}$ in period $t_{2}$ were statistically significantly less, and the duration of "sitting" was significantly longer than in period $t_{1}$ (Table 3 ). In experimental animals, the length of track, $\mathrm{V}_{\mathrm{m}}$ and the amount of time of locomotion with speed more $30 \mathrm{~cm} / \mathrm{c}$ (running) in the period $t_{1}$ were significantly greater than in the same period in the control group. There were no differences in locomotion between groups in the period $t_{2}$. At the same time, experimental rats showed a statistically significant greater number of grooming acts in the $t_{2}$ period compared to control animals.

The effect of isolation on learning the conditioned reflex of bilateral avoidance

The control and experimental groups showed the ability to learn the conditioned reflex equally: the control criterion ( 9 conditioned avoidance responses in 10 consecutive trials) reached 5 control rats (62.5\%) and 9 experimental (53\%). Differences between groups were revealed in the learning rate. Control rats reached the learning criterion on the $32.4 \pm 3.78$ trial (mean \pm S.D.), experimental rats-earlier, on the $23.22 \pm 6.76$ trial. The differences between groups are statistically significant ( $\mathrm{p}=0.0273, \mathrm{U}$ test). The remaining indicators of learning the avoidance responses as well as escape latencies and the number of defecations during the training in control and experimental animals did not differ significantly.

\section{Discussion}

In the process of early ontogenesis, there is a certain sequence in the development of exploratory and defensive behavior aimed at adapting to a new situation. First, exploratory behavior is formed that allows to know the conditions of the new environment. Then defensive behavior will be matured. So, in the third week of life, young rats exhibit a higher exploratory activity compared to adults in a potentially threatening environment (the center of the "open field") [17] 
and later defensive behavior will develop that prevents a possible danger (appears in preference for the dark) [3].

The decrease of species-specific sensory influx in early ontogenesis influences the development of exploratory and defensive reactions. Earlier, we revealed a deceleration in the formation of a dark preference in rats reared by nulliparous females with insufficient maternal care in the first days after birth [3]. In rats separated from the mother from the $2^{\text {nd }}$ to the $13^{\text {th }}$ postnatal days, a diminution of the passive-defensive freezing response at the age of 26 days (the period of maximum appearance of freezing in intact developing rats) is observed in comparison with the control rats [11], which can also be associated with a retardation in the formation of defensive behavior.

It is known that the behavior in the EPM is different in animals subjected to social isolation in early ontogenesis. Moreover, the change in behavior depends on the isolation method. Thus, the complete absence of social contacts with siblings during of milk nursing period led to an increase in the amount of time spent in open arms [18]. Daily 3-hour separation of the litter from the mother in the first two or three weeks of life, on the contrary, reduced this indicator [19] [20]. In our work, a complete 3-hour social deprivation of pups was performed from the $2^{\text {nd }}$ to the $8^{\text {th }}$ day of life. The effect of complete social isolation of the pups from the mother and siblings has two negative components: firstly, the restriction of species-specific sensory influx, and secondly, the stressful effect. The data obtained by us on changes in behavior in the EPM can indicate both a disturbance of the formation of a species-specific dark preference response and increased emotional reactivity, which determines the exploration of a potentially dangerous space. If we agree that any behavior is motivated, it should be recognized that social isolation in early ontogenesis slows down the formation of the need for defensive behavior.

A relatively unexpected result was obtained when studying the open field behavior of control animals during the first and second five-minute test periods. It was found that the locomotor activity of control rats in these periods does not differ, while previous studies have shown a decrease in the activity of intact rats Wistar in the second period of the test [15]. Probably, we observed the specifics of behavior in WAG/Rij rats genetically predisposed to absence epilepsy, which is expressed in the absence of a decrease in emotional reactivity during $10 \mathrm{mi}$ nutes of testing rats in an open field. In experimental animals, a decrease in activity in the second 5-minute test period occurred. However, the locomotor activity at this time was similar to identified in control animals. During the first five test minutes the locomotion was higher in experimental rats than in control animals what could be a manifestation of increase emotionality.

When 6-month-old animals were learned the avoidance conditioned reflex in shuttle-box with negative pain reinforcement, a more rapid formation of a stable reflex was found in experimental animals as compared to control ones. This is consistent with data on an increase in the rate of learning the avoidance condi- 
tioned reflex of adult Wistar rats exposed to daily 4-hour social isolation from the $1^{\text {st }}$ to the $21^{\text {st }}$ day of life [12]. Perhaps the increased emotional excitability and stress reactivity in experimental animals, identified in previous tests, induces a higher sensitivity to a threatening situation and increases the motivation to learn defensive behavior in adulthood.

\section{Conclusions}

Taken together, the data presented indicate systemic changes in the dynamics of the formation of the functions of the developing brain under the influence of the social isolation of newborns. It is likely that hormonal regulation is the mechanism involved in this process. Thus, it was found that even partial social isolation (daily separation from the mother for 3 hours) in the first 2 or 3 weeks of life of rat pups alters the reactivity of the stress-realizing hypothalamic-pituitaryadrenal system [11] [19] [20] and causes a decrease in the number of glucocorticoid receptors in hippocampus on the $14^{\text {th }}$ day of life [11].

The revealed increase in emotional reactivity in WAG/Rij rats under the influence of social isolation in early ontogenesis may be a factor contributing to the development of genetically predetermined absence epilepsy.

\section{Funding}

This work was supported by the RFBR grant No. 18-013-00597 "Social factors aggravating the manifestation of the absence epilepsy".

\section{Conflicts of Interest}

The authors declare no conflicts of interest regarding the publication of this paper.

\section{References}

[1] Shishelova, A.Ju. and Raevsky, V.V. (2010) Effects of Vibrissectomy during Early Postnatal Ontogenesis in Rat Pups on Behavioral Development. Neuroscience and Behavioral Physiology, 40, 671-677. https://doi.org/10.1007/s11055-010-9310-8

[2] Shishelova, A.Ju., Aliev, R.R. and Raevskiy, V.V. (2015) Early Sensory Experience Determines Variety of Exploratory Behavior in Adult Age. Experimental Psychology, 8, 73-84. (In Russ.)

[3] Shishelova, A.Ju. and Raevskiy, V.V. (2016) Influence of the Motherhood Experience on the Formation of Species-Specific Behavior of the Offspring in Early Ontogeny. Zhurnal Evoliutsionnoi Biokhimii i Fiziologii, 52, 347-353. (In Russ.) https://doi.org/10.1134/S0022093016050069

[4] Shishelova, A.Ju. and Raevskiy, V.V. (2018) The Influence of Pre- and Postnatal Factors on Early Behavior Formation. Doklady Biological Sciences, 479, 54-56. https://doi.org/10.1134/S0012496618020047

[5] Debiec, J. and Sullivan, R.M. (2017) The Neurobiology of Safety and Threat Learning in Infancy. Neurobiology of Learning and Memory, 143, 49-58. https://doi.org/10.1016/j.nlm.2016.10.015

[6] Van Hasselt, F.N., Boudewijns, Z.S., van der Knaap, N.J., Krugers, H.J. and Joels, M. 
(2012) Maternal Care Received by Individual Pups Correlates with Adult CA1 Dendritic Morphology and Synaptic Plasticity in a Sex-Dependent Manner. Journal of Neuroendocrinology, 24, 331-340. https://doi.org/10.1111/j.1365-2826.2011.02233.x

[7] Zuluaga, M.J., Agrati, D., Uriatre, N. and Ferreira, A. (2014) Social Aversive Stimuli Presented to the Mother Produce the Precocious Expression of Fear in Rat Pups. Developmental Psychobiology, 56, 1187-1198. https://doi.org/10.1002/dev.21199

[8] Sitnikova, E. (2011) Neonatal Sensory Deprivation Promotes Development of Absence Seizures in Adult Rats with Genetic Predisposition to Epilepsy. Brain Research, 1377, 109-118. https://doi.org/10.1016/j.brainres.2010.12.067

[9] Sitnikova, E., Rutskova, E.M. and Raevsky, V.V. (2015) Reduction of Epileptic Spike-Wave Activity in WAG/Rij Rats Fostered by Wistar Dams. Brain Research, 1594, 305-309. https://doi.org/10.1016/j.brainres.2014.10.067

[10] Sitnikova, E., Rutskova, E.M. and Raevsky, V.V. (2016) Maternal Care Affects EEG Properties of Spike-Wave Seizures (Including Pre- and Postictal Periods) in Adult WAG/Rij Rats with Genetic Predisposition to Absence Epilepsy. Brain Research Bulletin, 127, 84-91. https://doi.org/10.1016/j.brainresbull.2016.08.019

[11] Litvin, Y., Tovote, P., Pentkowski, N.S., Zeyda, T., King, L.B., Vasconcellos, A.J., Dunlap, C., Spiess, J., Blanchard, D.C. and Blanchard, R.J. (2010) Maternal Separation Modulates Short-Term Behavioral and Physiological Indices of the Stress Response. Hormones and Behavior, 58, 241-249. https://doi.org/10.1016/j.yhbeh.2010.03.010

[12] Pryce, C.R., Bettschen, D., Nanz-Bahr, N.I. and Feldon, J. (2003) Comparison of the Effects of Early Handling and Early Deprivation on Conditioned Stimulus, Context, and Spatial Learning and Memory in Adult Rats. Behavioral Neuroscience, 117, 883-893. https://doi.org/10.1037/0735-7044.117.5.883

[13] Lapiz-Bluhm, M.D.S., Bondi, C.O., Doyen, J., Rodriguez, G., Bédard-Arana, T. and Morilak, D.A. (2008) Behavioral Assays to Model Cognitive and Affective Dimensions of Depression and Anxiety in Rats. Journal of Neuroendocrinology, 20, 1115-1137. https://doi.org/10.1111/j.1365-2826.2008.01772.x

[14] Henry, B.L., Minassian, A., Young, J.W., Paulus, M.P., Geyer, M.A. and Perry, W. (2010) Cross-Species Assessments of Motor and Exploratory Behavior Related to Bipolar Disorder. Neuroscience \& Biobehavioral Reviews, 34, 1296-1306. https://doi.org/10.1016/j.neubiorev.2010.04.002

[15] Markel, A.L., Galaktionov, Ju.K. and Efimov, V.M. (1988) Factor Analysis of Rat Behavior in Open Field Test. Zh Vyssh Nerv Deiat Im I P Pavlova, 38, 855-863. (In Russ.)

[16] Guillazo-Blanch, G., Nadal, R., Vale-Martínez, A., Martí-Nicolovius, M., Arévalo, R. and Morgado-Bernal, I. (2002) Effects of Fimbria Lesions on Trace Two-Way Active Avoidance Acquisition and Retention in Rats. Neurobiology of Learning and Memory, 78, 406-425. https://doi.org/10.1006/nlme.2002.4073

[17] Smith, K.S. and Morrell, J.I. (2007) Comparison of Infant and Adult Rats in Exploratory Activity, Diurnal Patterns, and Responses to Novel and Anxiety-Provoking Environments. Behavioral Neuroscience, 121, 449-461. https://doi.org/10.1037/0735-7044.121.3.449

[18] Li, Y.-Q., Wang, X.-Y., Zhai, H.-F., Zheng, Y.-Q., Zhang, X.Y., Kosten, T. and Lu, L. (2008) Effects of Early Postnatal Sibling Deprivation on Anxiety and Vulnerability to Cocaine in Offspring Rats. Psychopharmacology, 199, 245-253.

https://doi.org/10.1007/s00213-008-1169-9 
[19] Dandi, E., Kalamari, A., Touloumi, O., Lagoudaki, R., Nousiopoulou, E., Simeonidou, C., Spandou, E. and Tata, D.A. (2018) Beneficial Effects of Environmental Enrichment on Behavior, Stress Reactivity and Synaptophysin/BDNF Expression in Hippocampus Following Early Life Stress. International Journal of Developmental Neuroscience, 67, 19-32. https://doi.org/10.1016/j.ijdevneu.2018.03.003

[20] Daniels, W.M., Pietersen, C.Y., Carstens, M.E. and Stein, D.J. (2004) Maternal Separation in Rats Leads to Anxiety-Like Behavior and a Blunted ACTH Response and Altered Neurotransmitter Levels in Response to a Subsequent Stressor. Metabolic Brain Disease, 19, 3-14. https://doi.org/10.1023/B:MEBR.0000027412.19664.b3 